\title{
Os filmes e o pensamento de Ed Pincus: o cinema direto em direção à autobiografia
}

\author{
Gabriel Kitofi Tonelo*
}

Resumo: A obra de Ed Pincus apresenta-se como um dos desdobramentos do cinema direto na década de 1970. À frente do MIT Film Section, a produção intelectual e filmográfica de Pincus evidencia uma proposta de cinema direto autobiográfico. Exporemos conceitualmente este cenário a partir de fontes primárias de informação, bem como de uma análise de Diaries (1971-1976), seu mais importante documentário.

Palavras-chave: Ed Pincus; documentário autobiográfico; cinema direto; MIT Film Section; Cambridge.

Resumen: La obra de Ed Pincus se presenta como uno de los desdoblamientos del cine directo en la década de 1970. Al frente del MIT Film Section, la producción intelectual y filmográfica de Pincus evidencia una propuesta de cine directo autobiográfico. Buscaremos exponer conceptualmente este escenario a partir de fuentes primarias de información, así como de un análisis de Diaries (1971-1976), su principal documental.

Palabras clave: Ed Pincus; documental autobiográfico; cine directo; MIT Film Section; Cambridge.

\begin{abstract}
Ed Pincus' oeuvre may be seen as a development of the American direct cinema of the 1970s. Leading the MIT Film Section, Pincus' intelectual and cinematographic work evidences the proposal of a direct-autobiographic cinema. I will seek to expose conceptually this scenario through the use of primary information sources, as well as through an analysis of Diaries (1971-1976), his most important documentary. Keywords: Ed Pincus; autobiographical documentary; direct cinema; MIT Film Section; Cambridge.
\end{abstract}

Résumé: L'œuvre d'Ed Pincus peut être considérée comme l'un des développements du cinéma direct américain des années 1970. À la tête du MIT Film Section, l'œuvre intellectuelle et cinématographique de Pincus témoigne de la proposition d'un cinémadirect autobiographique. Nous chercherons à exposer conceptuellement ce scénario à

* Universidade Estadual de Campinas - UNICAMP, Instituto de Artes, Programa de Pós-Graduação em Multimeios. 13083-854, Campinas, Brasil.

E-mail: gtonelo@gmail.com

$\mathrm{O}$ artigo é um recorte parcial da pesquisa de doutorado "O Documentário Autobiográfico: O cinema de Cambridge e a obra de Ross McElwee", realizada com bolsa da Fundação de Amparo à Pesquisa do Estado de São Paulo (FAPESP), sob o processo de número 2013/08742-6.

Submissão do artigo: 14 de dezembro de 2017. Notificação de aceitação: 30 de janeiro de 2018.

Doc On-line, n. 23, março de 2018, www.doc.ubi.pt, pp. 129-157. 
travers l'utilisation de sources d'information primaires, ainsi qu'à travers une analyse de Diaries (1971-1976), son documentaire le plus important.

Mots-clés : Ed Pincus ; documentaire autobiographique ; cinéma direct ; MIT Film Section ; Cambridge (Mass.).

\section{Introdução e Estado da Questão}

Ed Pincus (1938-2013) é um documentarista estadunidense que iniciou sua carreira cinematográfica na década de 1960. Diaries (1971-1976), diário filmado que realizou entre 1971 e 1976, é o documentário pelo qual o cineasta é mais reconhecido. A cobertura jornalística da ocasião de sua morte, em 2013, foi predominantemente voltada à acepção de Pincus como um dos principais pioneiros de um subgênero documentário hoje largamente difundido, o dos documentários autobiográficos ou pessoais. Este é um apontamento que vem sido defendido ao longo das décadas por diversos cineastas que tiveram contato com Pincus, seja diretamente, em sua atividade profissional como documentarista/professor, ou indiretamente, a partir do visionamento de seus filmes. É possível sustentar, entretanto, que a importância de sua obra para a história do cinema documentário é mais sentida pela influência que seus filmes tiveram na carreira de outros cineastas do que pelo alcance direto desses.

O caso mais notório é o de Ross McElwee, que realizou seus estudos cinematográficos entre 1975 e 1977 no departamento de cinema do MIT - o MIT Film Section -, fundado e comandado por Pincus e Richard Leacock. McElwee é um dos principais documentaristas-autobiógrafos estadunidenses, tendo dedicado praticamente toda sua carreira à exploração narrativa de temas ligados à sua vida individual e privada, em um movimento contínuo que já dura mais de três décadas e engaja sete de seus longas-metragens. Sherman's March (1986), seu filme mais conhecido, teve importância fundamental para a popularização da narratividade autobiográfica aplicada ao cinema documentário, sendo um filme que influenciou a decisão de diversos cineastas a experimentarem com a forma. Por sua vez, a década de 1990 trouxe consigo uma inundação de documentários autobiográficos na programação dos grandes festivais de cinema independente, como o de Sundance, e também em iniciativas de broadcasting como o P.O.V. - série documentária da rede estadunidense de televisão pública PBS (Aufderheide, 1997). Em relação à feitura de Sherman's March, Ross McElwee aponta que o filme fora influenciado "de todas as maneiras possíveis" pelo cinema autobiográfico de Ed Pincus (MacDonald, 1988). Esta é uma posição recorrentemente expressa por McElwee ao longo sua carreira, quando indagado acerca dos filmes que o motivaram em sua empreitada fílmica-autobiográfica. 
A obra e a influência de Ed Pincus para o desenvolvimento da noção de documentário pessoal/autobiográfico passaram ao largo da maneira que a questão foi abordada na teoria crítica do documentário a partir do final da década de 1980. As possibilidades deste tipo de abordagem foram mais comumente analisadas pela menção à obra de cineastas como o próprio Ross McElwee, além de Alan Berliner, Marlon Riggs, Jonas Mekas, Agnès Varda, Chantal Akerman, Jonathan Caouette, Kazuo Hara, Naomi Kawase, entre outros. Algumas razões para a ocorrência deste fato podem ser levantadas. Uma delas consiste no dado de que nos primeiros anos da década de 1980, após a finalização de Diaries (1971-1976), Ed Pincus mudou-se permanentemente de Boston para a área rural do estado de Vermont, trabalhando no cultivo de flores e interrompendo suas atividades tanto em relação à produção cinematográfica quanto à docência, pesquisa e escrita acadêmica no campo do cinema. O hiato de Pincus para com quaisquer comprometimentos cinematográficos sustentou-se por décadas, sendo quebrado apenas na metade da década de 2000, poucos anos antes de sua morte, quando se juntou à cineasta Lucia Small para a realização de dois filmes (The Axe in the Attic [2007] e One Cut, One Life [2014]) e foi entrevistado por pesquisadores sobre sua carreira. Outro dado é o de que nenhum de seus filmes, entre eles Diaries (1971-1976), foram distribuídos em qualquer formato de visionamento caseiro, dificultando sensivelmente o acesso a eles até a retomada de suas atividades cinematográficas, no ano 2000.

Historicamente, os principais comentadores da obra e do pensamento de Ed Pincus foram teóricos e pesquisadores ligados à região de Cambridge e suas universidades - como ao MIT, mas, mais especialmente, à Universidade Harvard, onde Pincus lecionou nos primeiros anos da década de 1980. Deste grupo de teóricos podem-se mencionar William Rothman e Charles Warren, que em diversas de suas análises incluem o trabalho de Ed Pincus e a produção do MIT Film Section como parte da história do documentário moderno estadunidense (Warren, 1996, 2013 e 2016; Rothman, 1996 e 1997). Outro pesquisador incluído neste grupo e que merece destaque é Jim Lane. Lane foi aluno de Pincus na Universidade Harvard e participou do trabalho de distribuição de Diaries. Em sua produção teórica, Lane publicou um dos principais artigos dedicados à análise da carreira cinematográfica de Pincus como conjunto, no que concerne às mudanças epistemológicas e estilísticas atravessadas por seus filmes desde o início de sua carreira até a proposta autobiográfica de Diaries (Lane, 1997). Além disso, o autor publica em 2002 o livro "The Autobiographical Documentary in America" (Lane, 2002), no qual a carreira e a influência de Pincus para o desenvolvimento do documentário estadunidense são colocados em destaque. Na obra, Lane enxerga a narrativa de Diaries como fundadora da 
abordagem de "entrada de diários" (Journal-Entry Approach), termo cunhado para referir-se a narrativas documentárias autobiográficas investidas na manutenção do tempo cronológico e em uma acentuação de seu aporte referencial, a partir da herança do cinema direto.

A partir da década de 2010, a obra de Ed Pincus foi retomada analiticamente, em um período no qual existiram mostras e retrospectivas dedicadas a seu trabalho, bem como publicação de pesquisas aprofundadas acerca de seus filmes e do universo do documentário autobiográfico da região de Cambridge. Em especial, destacam-se as pesquisas de Scott MacDonald que levaram à publicação, em 2013, de "American Ethnographic Film and Personal Documentary: The Cambridge Turn" (MacDonald, 2013). Na obra, MacDonald realiza um importante trabalho de revisão histórica, analisando extensivamente o percurso da produção cinematográfica de Cambridge a partir de suas universidades e apontando sua contribuição para o desenvolvimento da noção de documentário autobiográfico no país. A publicação de MacDonald é a mais completa fonte de informação sobre as preocupações do cinema desenvolvido em Cambridge desde a da década de 1970 até a contemporaneidade, permitindo um olhar de coesão acerca da obra dos cineastas envolvidos nesta história, como Ed Pincus, Miriam Weinstein, Alfred Guzzetti, Ross McElwee, Robb Moss, Nina Davenport e outros. Diversas das entrevistas realizadas por MacDonald para o trabalho estão disponíveis no livro lançado no ano seguinte pelo autor, "Avant-Doc: Intersections of Documentary and Avant-garde Cinema" (MacDonald, 2014) - entre elas, provavelmente a última entrevista com Ed Pincus a ser publicada, dada a morte do cineasta em 2013. Talvez como parte dessa revisão acerca do lugar da obra de Pincus na história do cinema documentário, é interessante apontar a menção feita por Bill Nichols a Diaries (1971-1976) em uma de suas últimas publicações, "Speaking Truths with Film: Evidence, Ethics, Politics in Documentary", na qual o autor o sustenta pela primeira vez como "um filme pessoal inovador (groundbreaking)" (Nichols, 2015: 83).

É também no movimento de revisitação da obra de Ed Pincus que este artigo se insere. Em especial, propõe-se o esmiuçamento da relação entre cinema direto e autobiografia na proposta artística de Pincus, a partir de uma análise tanto histórica quanto conceitual. À ocasião da retrospectiva dos filmes de Ed Pincus promovida pelo Lincoln Center (Nova Iorque) em novembro de 2012, o crítico de cinema Tom Roston sugeriu o posicionamento do nome de Pincus junto ao de Frederick Wiseman, D. A. Pennebaker, Richard Leacock e dos irmãos Maysles como cineasta pioneiro do cinema não-ficcional estadunidense da década de 1960, tomando Diaries como sua obra-prima (Roston, 
2012). Entretanto, se considerarmos que se a premissa do cinema direto, em sua gênese, é a do recuo observativo da câmera e de uma postura sobretudo não-interventiva do cineasta em relação às pessoas filmadas, pode-se questionar como uma obra como Diaries (1971-1976) poderia encaixar-se neste aporte conceitual, visto que elementos como a participação e a reflexividade integram, parti pris, sua proposta autobiográfica. A elucidação desta questão encontra-se em diversos documentos que dizem respeito ao período vivenciado por Pincus e outros jovens alunos/cineastas que fizeram parte do episódio do MIT Film Section. A partir de artigos, escritos e entrevistas que dizem respeito ao momento - a maioria deles pouco explorados em textos críticos - pretendese oferecer uma reflexão acerca do aporte conceitual que baseou o pensamento de Pincus acerca de um fazer autobiográfico que enxergava a si próprio como "próximo passo" do cinema direto estadunidense, diante da virada tecnológica e ideológica vivenciada na década de 1970. Da mesma maneira, a incursão por este tipo de material torna-se subsídio para o entendimento da proposta cinematográfica de Pincus como contraponto a outras iniciativas do período que também dialogavam com noções como as de reflexividade ou mesmo autobiografia, como é o caso do Cinema-Vérité francês ou do cinema avant-garde estadunidense na forma de Stan Brakhage, Jonas Mekas e outros. Nosso entendimento é o de que a importância de Pincus em seu trabalho conceitual, que desembocou na experiência de Diaries, e em sua influência para com outros cineastas, foi o de desenvolver um dos moldes narrativos que passaram a integrar o rol de possibilidades insertas na noção de "documentário autobiográfico", que se popularizou na década de 1980 e que se desdobra até a produção contemporânea.

\section{A origem cinematográfica de Ed Pincus}

Nascido no Brooklyn, em Nova Iorque, em 1938, Pincus graduou-se em filosofia pela Universidade Brown em 1960. Em seguida, realizou pós-graduação na Universidade Harvard entre 1961 a 1964, obtendo o título de mestre. Seu interesse pelo cinema aconteceu a partir do visionamento de um dos filmes do primeiro momento do cinema direto estadunidense, Showman, lançado por Albert e David Maysles em 1962. O cineasta ressalta que sua admiração pelo filme aconteceu a partir da experimentação de um "sentimento místico da realidade, como (se pudesse) tocar sua textura" (Levin, 1971: 331). O realizador recorda-se do filme ao enfatizar os trechos em que os irmãos Maysles, ao filmarem pela luz da janela ou de maneira semelhante, "produziam reflexos (flares) na lente, tornando os grãos visíveis.". O diretor complementa: "Fiquei impressionado com a qualidade tátil destas tomadas e comecei a pensar 
mais seriamente sobre cinema." (MacDonald, 2014: 80). Tal interesse pela materialidade fílmica da realidade estabeleceu-se como o foco das atenções conceituais de Pincus a partir de então. Segundo Jim Lane, Pincus era profundamente influenciado "por discussões filosóficas a respeito da consciência, fenomenologia Kantiana, as ideias de Stanley Cavell que levaram à publicação de The World Viewed e as teorias de Walter Benjamin sobre o impacto político e social da reprodutibilidade técnica" (Lane, 1997: 4). Dessa forma, a reflexão acerca das possibilidades de captura da realidade e da representação da experiência vivida fizeram parte do processo de criação de seus filmes e apresentam-se nas escolhas metodológicas e narrativas que os guiam.

De sua produção da década de 1960 destacam-se dois filmes, realizados, portanto, em diálogo com a circunstância do cinema direto estadunidense: os documentários Black Natchez (1967, 60') e One Step Away (1968, 54'), ambos feitos em parceria com David Neuman. Black Natchez, filmado em 1965 e lançado em 1967, foi o primeiro filme lançado por Pincus. Realizado no contexto do movimento pelos Direitos Civis, o documentário foi filmado na cidade de Natchez, estado sul-estadunidense do Mississippi, onde começava a haver organização da comunidade negra em relação às reivindicações sociais. As tensões raciais na cidade eram potencializadas, ainda, pelo fato de Natchez ser também o centro de atividades da Ku Klux Klan na região. A temática do filme gira em torno do debate acerca das possibilidades de ação que poderiam ser tomadas pela população negra da cidade. Segundo o filme nos mostra, este debate dividia-se organizacionalmente em dois polos. Um deles era representado pelo NAACP (National Association for the Advancement of Colored People), organização fundada no início do século XX e que encontrava o seu poder na classe-média e na burguesia negra, empresários e pastores. Por seu lado, o NAACP demandava que a luta e a conscientização da população negra acontecessem através de uma via democrática, que buscasse assegurar, sobretudo, o registro e a possibilidade de voto dos afro-americanos. O contraponto ao NAACP concretizava-se no FDP (Mississipi Freedom Democratic Party), organização política dedicada a representar mais diretamente os negros pobres maior parte da população - e que estabelecia propostas de ação de viés mais assertivo, radical e revolucionário. Pincus acreditava que a melhor maneira de trazer à tona a dialética da circunstância seria a partir do emprego de algo similar à técnica narrativa dos irmãos Maysles (Levin, 1971: 331) - referindo-se à narrativização dos acontecimentos a partir do recuo observativo da câmera do som sincrônico como elemento imperioso à tomada e da montagem cronológica. 
Em Black Natchez, portanto, o ímpeto cinematográfico de Pincus partiu de seu interesse em participar e trazer conhecimento acerca dos protestos pela igualdade de Direitos Civis. O engajamento político do diretor em One Step Away, ainda que existente, concretiza-se de maneira diferenciada. Lançado em 1968, a circunstância ideológica que dominava o momento fomentava um tipo de produção de conhecimento tematicamente ligado à exploração das liberdades individuais. A segunda onda do feminismo estadunidense, continuando os movimentos pelos Direitos Civis e as demonstrações contra a Guerra do Vietnã, colocou em voga a noção de que o endereçamento de questões relativas à vida privada, individual, também diriam respeito à vida coletiva e política. Enfatizava-se o interesse público por um olhar para "dentro", de problemas da ordem do individual e da abordagem temática da instituição familiar, bem como das relações interpessoais que emergem deste universo. É neste sentido que em One Step Away, Pincus e Neuman engajam-se com esta demanda com base no trabalho de aspectos da cultura hippie - fenômeno amplamente difundido no momento. $\mathrm{O}$ eixo narrativo do filme consiste no acompanhamento de uma comunidade hippie em sua experiência de vida em uma cidade grande - no caso do filme, San Francisco. Tendo como protagonistas o casal Harry e Rickie em sua interação com outros membros do grupo, One Step Away concentra-se em narrar os questionamentos que permeavam o imaginário hippie naquela circunstância. Há, entre os protagonistas do filme, a desconfiança de sistemas de autoridade e de valores tradicionais. Sublinha-se o interesse do grupo pela vida comunal, pela experimentação de substâncias como o LSD, pelo consumo de bens restritamente dedicados a fins de subsistência e por alternativas às uniões afetivas monogâmicas.

De algumas maneiras, portanto, One Step Away antecede a exploração de temáticas relativas às liberdades individuais que é acontece em Diaries (19711976), seu projeto seguinte. Contudo, diferentemente da acepção de uma metodologia de recuo observativo da câmera, mais ligada à noção clássica de cinema direto, encontrada em Black Natchez e One Step Away, em Diaries Pincus decide virar a câmera para si próprio e para o núcleo íntimo no qual estava inserido, realizando uma narrativa de matizes decididamente autobiográficas. No filme, o realizador registrou o desenvolvimento de eventos de sua vida privada entre os anos de 1971 e 1976, em um período marcado por experimentações em um campo marital, social e laboral. Pincus fez de si próprio e das pessoas próximas de si - sua família, amigos íntimos, amantes - os personagens de sua empreitada. O eixo temático de Diaries consiste nos conflitos atravessados pela família Pincus no período de cinco anos. Estes conflitos são pautados, sobretudo, pela decisão do diretor e sua esposa de vivenciarem 
uma experiência de casamento aberto, no qual ambos poderiam manter relações extramaritais. Diaries foi finalizado alguns anos depois e sua versão final consiste em um filme de três horas e vinte minutos de duração. A partir da experiência particular da família Pincus, o filme apresenta o retrato de uma época. As possibilidades alternativas de família e trabalho evocam um cenário vivido por parte da juventude progressista norte-americana a partir da segunda metade da década de 1960.

Em Diaries, Ed Pincus desenvolve uma narrativa autobiográfica cuja proposta artística advém de preocupações conceituais ainda relativas à tradição do cinema direto estadunidense - levando-a a um passo ainda não explorado e fazendo-se um teste desse tipo de metodologia em sua aplicação autobiográfica. A figura de Pincus e as reflexões que o levaram a realizar Diaries influenciaram outros cineastas que seguiram pelo caminho da autobiografia fílmica no país e que mantiveram contato com o realizador no período do desenvolvimento desse projeto. A empreitada do MIT Film Section é um episódio interessante na história do documentarismo estadunidense, a cuja produção um olhar dedicado faz-se necessário para o entendimento do conjunto estéticometodológico que envolve o projeto de Diaries.

\section{A produção do MIT Film Section e o cinema direto estadunidense dos $\operatorname{anos} 1970$}

Particularmente pulsante no que concerne à efervescência de debates em relação ao cinema documentário do período, o MIT Film Section foi o departamento de pesquisa, ensino, produção e inovação cinematográfica do Massachusetts Institute of Technology (MIT). Fundado em 1967, o departamento foi liderado por Ed Pincus e Richard Leacock, responsáveis pelas principais atividades de docência do centro. A "época de ouro" do MIT Film Section concerniu desenvolvimentos da arte cinematográfica aplicadas ao documentário e à formação de cineastas a partir da instauração de um programa de mestrado, em 1974. Tratava-se de um programa de dois anos com enfoque predominantemente prático e voltado à realização documentária. Havia a noção enfática de que os cineastas formados no departamento deveriam dominar o núcleo duro de funções da produção fílmica (imagem/som e montagem) a fim de poder desempenhar qualquer um dos papeis, ou todos eles, na construção de narrativas documentárias. Durante o curso, os alunos realizavam um ou mais de seus próprios filmes, que deveriam ser finalizados e entregues como 
trabalhos de conclusão, ${ }^{1}$ juntamente com um "memorial" descritivo-analítico em que justificavam as escolhas narrativas empregadas nas obras.

O trabalho de docentes e alunos no MIT Film Section entre 1967 e 1980 concentrou-se predominantemente no debate e no desenvolvimento de questões ligadas ao documentário a partir do legado do cinema direto norte-americano. $\mathrm{O}$ fomento à produção e ao desenvolvimento de técnicas e metodologias que simplificassem (e barateassem) cada vez mais o registro cinematográfico imagético-sonoro sincrônico impulsionou o interesse de muitos de seus alunos pelo curso oferecido. Também neste momento pensava-se na inovação tecnológica (característica bastante relacionada à filosofia operante do MIT, de maneira geral) relacionada ao cinema documentário como possibilitadora de uma inovação epistemológica - da própria natureza do conhecimento que era produzido por filmes documentários. Em parte, tratava-se de pensar o syncsound como característica irrevogável do processo cinematográfico e do registro fílmico do mundo. O cineasta Alfred Guzzetti, realizador caro à história do cinema de Cambridge e que lecionava em Harvard no período, relata que "eles (no MIT) achavam que uma vez que conseguissem fazer funcionar esta máquina do sync-sound, ela poderia dizer-nos verdades sobre a sociedade que nunca tínhamos conhecido" (MacDonald, 2014: 111. Tradução nossa.). Durante os anos do MIT Film Section, Leacock, Pincus e uma trupe de técnicos desenvolveram aperfeiçoamentos para o sync-sound tanto na bitola de $16 \mathrm{~mm}$ quanto na de super- $8 \mathrm{~mm}$, sendo que o uso de ambos os sistemas foi encorajado aos estudantes para suas produções.

O desenvolvimento de câmeras e gravadores menores e menos custosos possibilitou o registro fílmico a partir de uma "equipe de uma pessoa só" (oneperson-crew), na qual o próprio cineasta seria responsável pela captação de imagem e som sincrônico no momento da tomada. O desenvolvimento desta metodologia foi imprescindível para o tipo de empreitada fílmica proposta no MIT Film Section. Em especial, destacam-se as possibilidades de narratividade autobiográfica que eram calcadas nas inovações tecnológicas desenvolvidas no departamento. Ed Pincus foi o principal articulador do debate permeado no local durante a década de 1970 que apontava para o emprego de narratividades autobiográficas como um "próximo passo" do cinema direto estadunidense. ${ }^{2}$

1. Em sua autobiografia, Richard Leacock constata que foram realizados mais de quarenta filmes de conclusão de curso no MIT, alguns de "reconhecimento considerável", segundo ele, como Charleen de Ross McElwee, Premature, de David Parry, e Space Coast, de Ross McElwee e Nicholas Negroponte. (Leacock, 2002: 283)

2. Richard Leacock frisa o distanciamento que tinha de Ed Pincus em relação a esta questão, afirmando que "Pincus estava interessado em filmes 'diarísticos'; eu sentia que isto era impossível. Alguns estudantes foram pelo meu caminho, outros seguiram pelo caminho dele. Ainda penso sobre isto e continuarei a fazê-lo." (Leacock, 2002: 308). 
Ainda que com nortes metodológicos afins, o tipo de documentário autobiográfico relacionado ao MIT Film Section apresentava-se como reação à primeira fase do cinema direto, tanto em um ponto-de-vista temático quanto metodológico. Como característica de um novo momento, passou a existir o ímpeto de representação de universos temáticos mais diretamente ligados à figura individual dos próprios cineastas. Neste caso, havia menos interesse em filmar e construir conhecimento a partir da história de indivíduos públicos ou personagens de destaque (como John F. Kennedy, em Primary [1960] ou Crisis [1963], ou Jane Fonda, em Jane [1962]). Buscava-se tematizar a experiência estadunidense naquele momento específico a partir da vida individual do realizador, de seu cotidiano e daquilo que sua interação com as pessoas mais próximas de si poderia oferecer, frequentemente em uma esfera familiar. A noção de observação "mosca-na-parede" e a subtração narrativa de elementos que revelassem a presença dos cineastas na tomada dão lugar à participação e à ênfase da interação do realizador com as pessoas no momento da filmagem.

Os trabalhos finais redigidos pelos alunos do MIT Film Section (como McElwee, 1977; Rance, 1977; ou Moss, 1979) evidenciam como o desenvolvimento das possibilidades metodológicas do cinema direto - e o florescimento para uma inclinação ao documentário autobiográfico - estavam no cerne das questões discutidas no departamento. Discutiam-se possibilidades narrativas que variavam entre o emprego de uma postura observativa versus a interação/participação do realizador com o mundo ao redor; a proximidade ou o distanciamento do cineasta com o "objeto" fílmico; ou ainda a maneira através da qual as configurações de equipe, equipamento e metodologia de filmagem adequavam-se a determinado projeto. A dissertação de Richard Peña ${ }^{3}$ entregue para a conclusão do curso no MIT (Peña, 1978) busca problematizar o estado da arte do documentário moderno estadunidense, na forma do cinema direto. Em seu trabalho, o autor traça uma trajetória histórica que atravessa a produção do grupo Drew e o cinema de Jean Rouch, reconhecendo a contemporaneidade da produção de Ed Pincus e estabelecendo uma avaliação crítica do trabalho feito pelos estudantes do MIT Film Section. Peña, como

3. Richard Peña, atualmente professor da Columbia University, foi assistente de edição em Diaries (1971-1976). A história de Peña e sua relação com o MIT Film Section apresenta uma interessante conexão com o Cinema Brasileiro e latino-americano. Em entrevista realizada para a pesquisa originária deste artigo, Peña relata que a decisão de estudar no MIT Film Section partiu de sua experiência no Brasil entre 1974 e 1975 . Neste momento, travou contato com Paulo Emilio Salles Gomes, Carlos Augusto Calil e outros pesquisadores. Peña estava interessado na ideia do "acesso" à produção cinematográfica em países latino-americanos. Apesar do apreço pelo cinema de Leacock, Pennebaker e outros cineastas do grupo do Cinema Direto estadunidense, sua ida ao MIT Film Section determinou-se pela ciência de que o departamento experimentava com bitolas menores, como o Super-8, e outros tipos de inovações do aparato cinematográfico. Desta maneira, o pesquisador interessava-se pela simplificação e barateamento da produção fílmica em prol de sua desvinculação de uma ótica profissionalizante e elitista. 
outros teóricos/cineastas que viveram este momento cinematográfico "de dentro" da experiência, enxergava a produção contemporânea como uma reação ao cinema direto clássico, sublinhando os novos questionamentos temáticos, metodológicos e éticos que eram suscitados pelos filmes desenvolvidos no departamento:

Pode-se ver como a obra de Pincus oferece um exemplo da evolução do cinema-vérité americano para longe do modelo Drew em certa direção (...) O indivíduo extraordinário é substituído (...) pelo cineasta ele próprio, de certa maneira. Repentinamente, os "objetos" do cinema-vérité Americano viram-se e encaram a câmera. " (Peña, 1978: 26. Tradução nossa.).

Peña ainda constata que, naquele momento, o cinema direto e, especialmente, o trabalho vindo do MIT, constituía a única vanguarda significativa do cinema estadunidense (Peña, 1978: 5). Segundo o autor, "certamente o trabalho dos docentes e dos funcionários, assim como parcela significativa do trabalho dos alunos, está vislumbrando novos caminhos no cinema, cujos efeitos ainda serão sentidos" (Peña, 1978: 6). A ênfase em relação ao aporte autobiográfico encontrado na produção do MIT Film Section também é apontada pelo aluno do departamento David Parry. Parry, que realiza ao longo do curso o documentário Premature - sobre o nascimento prematuro de sua primeira filha, nascida em uma gestação de seis meses - sugere que se o cinema direto dos anos 1960 poderia ser entendido através da metáfora da "mosca na parede", a produção da década de 1970 seria metaforizada pela "mosca no espelho" (Parry, 1979: 6). Para Parry, a produção do MIT Film Section revela que, naquele momento "a verdade subjetiva tornou-se o espécime mais nobre para análise, e a autobiografia torna-se quase que um "cartão de visitas"” (Parry, 1979: 6). Para além de filmes já citados, como Premature, de David Parry, e da produção de Ross McElwee, cineastas como Robb Moss (Absence [1981], Riverdogs [1982], The Tourist [1991], The Same River Twice [2002]), Mark Rance (Mom [1978] e Death and the Singing Telegram [1983]), Jeff Kreines (The Plaint of Steve Kreines as Recorded by his brother Jeff [1974]), Joel DeMott (Demon Lover Diary [1980]) e Ann Schaetzel (Breaking and Entering [1980]) também podem ser relacionados à produção autobiográfica que permeou as atividades do MIT Film Section.

\section{Ed Pincus e a defesa do alicerce conceitual do cinema direto}

Pode-se, entretanto, questionar: se a noção mais clássica de "cinema direto" sugere um alicerce metodológico no qual o cineasta encontra-se em posição recuada, observativa e/ou não-interventiva no que concerne seu registro fílmico em relação às pessoas filmadas e o mundo que as circunda, de que 
maneira uma proposta autobiográfica como a de Pincus poderia relacionar-se conceitualmente com este fenômeno? O contato com material primário de informação apresenta-se como subsídio para o entendimento em relação a esta questão, sobretudo em entrevistas e escritos do cineasta realizados à época. Uma destas fontes consiste no debate travado entre Pincus e o cineasta francês Jean Rouch, publicado na compilação de entrevistas "Documentary Explorations”, realizadas pelo autor G. Roy Levin em 1971 (Levin, 1971). A obra de Levin compõe-se da edição de quinze entrevistas com importantes documentaristas do período, como Lindsay Anderson, Albert e David Maysles, Richard Leacock e D. A. Pennebaker, para além de Pincus e Rouch. As entrevistas de Levin marcam cronologicamente o tipo de debate que permeava o imaginário do documentarismo do início da década de 1970, em diversas de suas vertentes. É possível dizer que o diálogo travado entre Pincus e Rouch evidencia, de maneira geral, a postura antagônica entre o documentário moderno em sua forma norte-americana e francesa, que vem à tona a partir da defesa de aspectos narrativos e estilísticos aplicados ao documentário detectáveis nos argumentos de cada um.

As posições antagônicas de Pincus e Rouch emergem a partir do comentário de ambos acerca dos filmes dirigidos por Frederick Wiseman, cuja carreira era recém-iniciada. É interessante mencionar que, diferentemente das proposições que emergiam no MIT Film Section encabeçadas por Pincus, a obra de Wiseman não se engaja enfaticamente na defesa de uma postura metodológica de participação e reflexividade da figura do cineasta nas tomadas e no eixo narrativo dos filmes - o que eventualmente culmina em uma temática autobiográfica, no caso de Pincus e outros. Grosso modo, Wiseman opta por uma construção narrativa que se pauta no criterioso recuo observativo da câmera, sendo esta uma metodologia que pouco mudou durante os cinquenta anos de carreira do diretor. Mesmo assim, pode-se sustentar que a obra de Wiseman está mais próxima, epistemologicamente, do cinema realizado no MIT Film Section - em sua relação com o cinema direto estadunidense - do que à obra de Rouch. A interpretação do debate entre Rouch e Pincus pode trazer esclarecimento à questão. Na entrevista com o realizador francês, o entrevistador G. Roy Levin pergunta sua opinião a respeito de Titicut Follies (1967), longametragem de estreia de Wiseman. Rouch, apesar de evidenciar o apreço que tinha por John Marshall (co-diretor e fotógrafo do filme), reage ao filme com "horror":

Jean Rouch: Não há esperança. Não há absolutamente nada positivo naquilo. Nada. É um relato negativamente certo de si próprio sobre uma situação. Levin: Mas você o vê como "verdadeiro"? 
Jean Rouch: Então você tem de expressar isso. Eu gostaria que ele tivesse falado algo, expressado qual é sua tese. Aquilo (o filme) significa que temos de suprimir este sistema policial? Ou que se deve permanecer em um hospital psiquiátrico? Significa que aquele hospital, em particular, é uma desgraça? Não é óbvio. Talvez seja óbvio para os americanos, mas não para estrangeiros. (...) É como se você fosse a um hospital para crianças retardadas e não mostrasse nada além disso. Há uma fascinação com o horror aqui (nos EUA). Por exemplo, um filme sombrio como Noite e Neblina é um filme profundamente humano precisamente porque existe a narração, porque há uma mão que guia. Em Titicut Follies não existe nenhuma (guia), é um relato certificado, que poderia talvez ser interpretado como um relato cínico e sadomasoquista. Eu perguntei a John Marshall... qual o nome do jovem garoto com quem ele fez o filme?

Levin: Wiseman.

Jean Rouch: Wiseman. Qual foi a reação de Wiseman diante de tudo aquilo? Ele teve prazer naquilo? Ele ficou feliz? E John Marshall disse que existia uma fascinação com o lugar, e que esta fascinação era uma fascinação com o horror - que é uma fascinação estranha e que devia ter sido expressada (no filme). (Levin, 1971: 141-142. Tradução nossa.).

A crítica de Rouch a Wiseman e Marshall a respeito de Titicut Follies é endereçada por G. Roy Levin a Pincus na entrevista feita com o realizador, para o mesmo livro. Na ocasião, Pincus rebate vigorosamente os apontamentos de Jean Rouch:

Ed Pincus: Em primeiro lugar, acho que Jean Rouch tem mais expectativas em relação aos cineastas do que eu tenho. Olhe, Wiseman estava preocupado o suficiente em ir lá e passar alguns meses em Bridgewater ${ }^{4}$. Não sei quanto a você, mas eu não conseguiria passar três meses lá. David ${ }^{5}$ foi captar som direto lá um dia e me contou como era. Wiseman mostrou preocupação suficiente em fazer isto - ninguém mais o fez. Em segundo lugar, apenas o fato de estar lá filmando, silenciosamente, já foi muito mais forte do que seria o terror de "baixo nível" que um cineasta medíocre conseguiria realizar estando no local. De alguma maneira, aquele tipo de dureza e inexorabilidade era muito, muito mais forte. Em terceiro lugar, eu não estou interessado na solução de Frederick Wiseman para o problema, porque acho que ele não é capaz de dála. Não acho que seja problema dele. No nível mais primário, temos primeiro de ver as coisas - este é um exemplo de como fazer calúnia (em relação ao filme), quando ninguém nem ao menos tinha visto aquilo antes.

A outra coisa é que eu acho que Rouch... eu vi apenas um de seus filmes, Chronique d'un été, e achei simplesmente horroroso. Eu achei o nível de envolvimento dele pretensioso e risível. Eu achei aquele andar pelo corredor, conversando com seu assistente ${ }^{6}$ e discutindo um sistema de arte, realidade e atuação, obnóxio. Toda a sua noção de cinema é uma realidade totalmente

4. A instituição retratada em Titicut Follies.

5. David Neuman, parceiro de Pincus em praticamente todos seus filmes pré-Diaries.

6. Edgar Morin. 
criada para a câmera, criada pelo cineasta. A realidade tem o menor dos papéis em seu filme. (Levin, 1971: 367. Tradução nossa.).

Interpretando primeiramente a reação de Jean Rouch a Titicut Follies, é possível dizer que Rouch não enxerga no filme de Wiseman um propósito além do de expor o cotidiano assombroso de uma instituição como Bridgewater. Para Rouch, o filme parece não ser mais do que uma exposição dos espectadores a uma espécie de Freak-Show que busca satisfazer uma curiosidade quiçá sádica das pessoas que o assistem (e dos cineastas) em relação ao horror e ao abjeto. A comparação que Rouch faz a um filme como Noite e Neblina é contundente. Para Rouch, se um cineasta se dispõe a trabalhar narrativamente uma temática delicada ou polêmica, é imperativo que exista algum tipo de elaboração crítco-analítica de sua parte e que esta torne-se parcela integrante da narrativa que está sendo criada. Caso esta posição analítica esteja ausente, o filme cairia em um voyeurismo desnecessário. Rouch parece apontar certa predileção do público estadunidense por este tipo de conteúdo que, em sua visão, carece de desenvolvimento intelectual mais aguçado. ${ }^{7}$

Ed Pincus, por sua vez, rebate aos apontamentos de Rouch manifestando que o sucesso de Wiseman residiria, antes de tudo, no fato do cineasta ter passado meses acompanhando e filmando a instituição. Pincus ressalta que poucos cineastas teriam força de vontade o suficiente para vivenciar durante um longo período de tempo o dia-a-dia adverso de Bridgewater. Para cineastas como Pincus seria imprescindível que Wiseman dedicasse considerável tempo de trabalho (e muitos rolos de película) registrando o funcionamento da instituição que era objeto de seu filme. Sendo assim, somente a partir do engajamento do diretor com uma porção significativa do cotidiano e da interação entre pessoas e coisas que compõem o funcionamento natural da instituição, é que se criaria a possibilidade de trabalha-la narrativamente. A paciência no trato com a realidade em seu registro é peça fundamental para uma tentativa de fornecer ao espectador a possibilidade de experienciar determinada situação - a "sensação de estar lá", lembrando aqui uma expressão frequentemente utilizada por Richard Leacock, também usada como título de sua autobiografia (Leacock, 2002), e que remete às reflexões de Robert Drew originárias do cinema direto. Tendo sucesso nesta empreitada, o cineasta dará condições ao espectador de tirar suas próprias conclusões a respeito do tema, abstendo-se ele próprio de promover um comentário analítico mais demarcado a respeito do assunto a que se propõe abordar. Este comentário, ausente no caso do filme

7. A partir do final dos anos 1970 , Rouch teve um engajamento maior com a produção e a academia estadunidenses. Em 1977, o diretor leciona uma série de cursos de verão nos EUA, juntamente com John Marshall, Richard Leacock, e outros cineastas. Além disto, Rouch leciona na Universidade de Harvard durante quatro verões consecutivos, entre 1980 e 1983. 
de Wiseman, é justamente o que reivindica Jean Rouch. Sobre este aspecto Wiseman afirma, no mesmo conjunto de entrevistas realizados por G. Roy Levin: "(Meus filmes) têm um ponto de vista que te permitem - ou, esperançosamente, te pedem - para pensar, para que descubra o que você acha a respeito daquilo que está acontecendo" (Levin, 1971: 322. Tradução nossa.).

Levin realiza as entrevistas no início da década de 1970. A partir de sua compilação, é possível notar que ainda neste momento havia um debate intenso acerca das possibilidades de construção narrativa no cinema documentário, frente à virada tecnológica e epistemológica acarretada no início dos anos 1960. Os excertos das opiniões de Jean Rouch, Ed Pincus e Frederick Wiseman revelam que dez anos após o lançamento de filmes como Primary ou Chronique d'un été o conjunto de questões que envolvia as noções de cinema direto e cinema-vérité não trazia respostas unânimes entre os cineastas que fizeram parte desta história. A publicação do livro de entrevistas de Levin ocorre oito anos após o congresso convocado em 1963 pela agência nacional de radiodifusão e televisão francesa, a ORTF (Office de Radiodiffusion-Télévision Française), em Lyon, e que contou com os principais representantes do novo documentário francês e estadunidense. No clássico artigo "The Documentary Film as Scientfic Inscription", Brian Winston (1993) ocupa-se de expor o pensamento antagônico dos dois grupos em relação aos caminhos do documentário naquele momento. De maneira geral, a posição estadunidense (na forma de diretores como Robert Drew, os irmãos Maysles e Richard Leacock) era marcada pela crença da possibilidade de uma objetividade mimética do registro fílmico em relação à realidade material, proporcionada por uma estilística do recuo observativo da câmera e da supressão de elementos de reflexividade que evidenciassem o processo de feitura fílmica na própria narrativa. A perspectiva de uma posição narrativa "objetiva" de um filme em relação à representação da realidade era refutada de antemão por cineastas do grupo francês, como Jean Rouch ou Jean-Luc Godard. Para os representantes deste grupo, processos reflexivos que transpusessem à narrativa os aspectos de feitura fílmica e da presença autoral do cineasta e de sua equipe seria uma maneira de endereçar a "realidade da filmagem" de modo mais justo, ou mesmo "verdadeiro", vide Chronique d'un été.

É possível dizer que em 1970, no período das entrevistas realizadas por G. Roy Levin, a crença purista e cientificista da objetividade a partir de uma metodologia de recuo observativo da câmera e de uma montagem transparente dava sinais de desgaste, mesmo entre diversos cineastas do grupo americano. Ainda que de maneira geral muitos destes recursos continuassem a ser empregados em filmes de tais realizadores, pode-se afirmar que não existia o mesmo ímpeto 
aventureiro que motivou as experiências de Robert Drew na busca de uma possível "verdade" em relação ao registro do mundo em narrativas documentárias. Este é o caso do próprio Frederick Wiseman. Embora seus filmes partilhassem (e continuem partilhando) diversas das características que fizeram com que o cinema direto fosse vinculado a certa noção de "pretensão de objetividade", Wiseman sempre admitiu um forte ponto-de-vista subjetivo em relação a seu processo criativo, ${ }^{8}$ diferentemente da postura assumida por Drew, Leacock ou pelos irmãos Maysles no início de suas carreiras.

Neste momento, Ed Pincus também fez parte de uma leva de cineastas que se opunha criticamente às soluções narrativas e aos efeitos de dramaticidade dos filmes do grupo Drew, que eram vistas como mascaradas por uma aura de pretensão de objetividade. Entretanto, cabe questionar: se Pincus revela interesse pelos desdobramentos do cinema direto da década de 1970 em direção à desconstrução do mito da objetividade, à participação do cineasta na narrativa documentária e à possível exploração da figura individual do diretor como matéria-prima temática para os filmes, por que teria realizado uma crítica tão vigorosa de Chronique d'un été? Por que, para Pincus, o envolvimento de Rouch no filme seria "pretensioso e risível" e a realidade teria "o menor dos papéis" na narrativa?

É interessante pensar que a crítica de Pincus revela a posição do diretor dentro da tradição do cinema direto estadunidense, refletindo alguns valores não-negociáveis (ou pouco negociáveis) para esta escola de cineastas. Mesmo que neste momento Pincus e outros diretores já tivessem uma reação crítica, como frisado, à postura do "primeiro" cinema direto que se supunha o "portador do archote" da representação da realidade, existe ainda o apreço por registrar o mundo e sua realidade material a partir de uma observação paciente, bem como há um desgosto por situações deliberadamente provocadas para a encenação. Pincus entende que existe um mundo em complexo funcionamento independente da presença da câmera e há o desafio de qualquer cineasta em ao menos tentar representa-lo, respeitando o ballet da interação natural entre seres e as superfícies materiais que os circundam. Para o diretor, a construção narrativa de Frederick Wiseman em relação a Bridgewater em Titicut Follies não é um fato dado. Como Pincus frisa em sua resposta a Rouch para o entrevistador G. Roy Levin, ela é fruto do trabalho do cineasta de entender, capturar e reconstruir uma espécie de fluxo da realidade ao qual esteve exposto cotidianamente, durante meses. Este seria o caminho pelo qual o realizador poderia oferecer um relato narrativo que fizesse jus à experiência que viven-

8. Este ponto é trabalhado marcadamente na entrevista de Wiseman a G. Roy Levin em (Levin, 1971: 313-328). 
ciou, a "sensação de estar lá", oferecendo-a em forma de filme para a liberdade interpretativa dos espectadores.

Neste sentido, Pincus entende que Rouch apresenta uma postura arrogante ao reconhecer o filme de Wiseman como "mero fato". Segundo o realizador, nunca teria havido um movimento, entre os documentaristas franceses, de tentar representar o mundo em seu funcionamento independentemente da presença da câmera. Desta forma, o ataque de Rouch à metodologia empregada por Wiseman em um filme como Titicut Follies seria, para Pincus, uma crítica a um terreno ético com o qual o cineasta francês não teria experiência para colocar-se como figura de autoridade. Já em 1977, Pincus publica o artigo "New Possibilities in Film and The University", em que se posiciona criticamente em relação a elementos narrativos que julga pertencer ao universo do documentarismo francês:

Os franceses nunca experimentaram de verdade com a possibilidade de filmar o mundo independentemente da presença da câmera. Desde o início, o cinema deles reconhecia a câmera como uma ruptura do fluxo da realidade. Assim, nos primeiros filmes do Cinema-Vérité francês o cineasta está frequentemente presente como um guia e um manipulador dos eventos para a câmera (também em alguns filmes ficcionalizados do Cinema-Vérité estadunidense, como David Holzman's Diary). Nós raramente vemos interações espontâneas e eventos nestes filmes, mas em vez disso, o assunto dominante parece ser as pessoas falando sobre seus sentimentos. Os americanos eram céticos em relação à entrevista. As pessoas são cautelosas durante entrevistas, e apresentam uma espécie de imagem que pode ser interessante se também temos (no filme) seus momentos menos cautelosos, para que suas entrevistas sejam colocadas em perspectiva. Isto faltava nos filmes franceses. (...) Quando Godard queria referir-se à autenticidade do documentário em seus filmes, ele parece ter ido a uma abordagem Jean Rouchiana do mundo, entrevistando seus personagens, e os resultados sempre foram a parte mais fraca de seus filmes, arrogantes, pretensiosos e falsos. Pode-se indagar o que teria acontecido se sua busca pela autenticidade no documentário fosse inspirada pelo Cinema-Vérité estadunidense, com sua tradição de espontaneidade e do mundo independente à câmera. Quando mais tarde os cineastas estadunidenses tentaram examinar a influência da câmera no mundo, eles portavam uma tradição que tinha, em certa medida, testado as possibilidades da câmera tentando não provocar uma ruptura nele (no mundo). (Pincus, 1977: 177-178. Tradução nossa.).

No momento, Pincus acabara de filmar Diaries (1971-1976) e encontravase no período de pausa de cinco anos entre o término da filmagem e o processo de montagem. Seu escrito refere-se justamente ao tipo de questão que buscava endereçar no filme. Diaries apresenta uma qualidade distinta da relação autorreflexiva entre cineasta e câmera que, neste caso, culmina em uma abordagem autobiográfica. Diferentemente do que aponta em relação ao documentário francês nos moldes de Chronique d'un été, Pincus entende que a presença, ou 
a ênfase, da câmera e do cineasta na narrativa fílmica não se traduz em uma ruptura total do fluxo da realidade. Em Diaries, Pincus buscará explorar a adição do elemento "câmera" à sua atmosfera doméstica, familiar e social. O desafio consistiria em engajar sua declarada intenção em realizar um filme às nuances e delicadezas de sua vida individual por um período de cinco anos. Existe, portanto, um "caldeirão" pré-fílmico que compõe a circunstância sobre a qual Pincus debruça-se.

Em sua análise sobre documentários autobiográficos publicada em 1994, "Autobiography as Interaction", a autora Susanna Egan toca neste mesmo ponto ao sugerir documentários autobiográficos que, como procedimento metodológico, "posicionam a vida pré-textual como controladora da narrativa e usam o meio fílmico bastante explicitamente como maneira de registrar as surpresas da contingência” (Egan, 1994: 611. Tradução nossa). É possível sustentar que a experiência de cinema direto autobiográfico de Diaries é uma das principais pioneiras em relação ao teste deste tipo de possibilidade. No filme, Ed e Jane Pincus vivem uma circunstância ideológica particular, criando dois filhos pequenos em meio à efervescência das questões evocadas pelos movimentos de liberdades individuais. Estas questões culminam em experimentações no âmbito familiar, matrimonial e das relações de trabalho que regem a vida do casal Pincus. A este cenário, potencialmente instável por si só, é adicionado o fator "Ed Pincus e sua câmera", que entra em vibração com os outros elementos que fazem parte da vida da família naquele momento. Ao longo dos cinco anos de sua empreitada, o realizador evidencia narrativamente as diferentes maneiras pelas quais a presença da câmera e da "intenção fílmica" se relacionam e afetam o curso de sua vida individual. Para Pincus, portanto, seria fundamental frisar que a câmera não é responsável pela criação de uma situação totalmente nova e, sim, por um flexionamento entre as partes que pode adquirir contornos complexos. A relação cineasta-câmera-mundo testada por Diaries seguiria o mesmo "respeito" da tradição do cinema direto estadunidense em relação à intenção de retratar o mundo em seu funcionamento, entretanto flexionado pela presença da câmera e pela intenção autobiográfica. Em linhas conceituais, esta será a cartilha seguida pelo cinema autobiográfico de Cambridge, que tem sua gênese propriamente na experiência do MIT Film Section e que se desdobra pelas décadas seguintes na região.

\section{A experiência autobiográfica de Diaries (1971-1976)}

Em 1971, Ed Pincus dá início à filmagem de Diaries com a proposta de filmar eventos de sua vida cotidiana, em diversas frentes, pelo período de cinco anos. A experiência autobiográfica pensada por Pincus deveria contar, ainda, 
com a espera de mais cinco anos após o término das filmagens antes da montagem do material - Diaries foi finalizado apenas em 1981. A versão final consiste em um filme de três horas e vinte minutos de duração. Apesar de ter sido terminado apenas no início da década de 1980, Pincus exibia trechos (rushes) do material bruto do filme para os alunos do MIT Film Section na década de 1970 como material didático (McElwee, 2012). Diretamente, Diaries pôs à prova escolhas metodológicas e estruturas narrativas que se tornaram a marca registrada do documentário autobiográfico de Cambridge. As mais importantes destas estruturas seriam a acepção da equipe de uma pessoa só (one-person-crew) como condição irrevogável para o sucesso da empreitada autobiográfica; o registro imperioso (bem como sua utilização na narrativa) de imagem com o respectivo som sincrônico (sync-sound) que a acompanha no momento da tomada; a construção da narrativa autobiográfica a partir de uma macroestrutura cronológica; e o realce da figura do cineasta no momento da tomada fílmica a partir de seu endereçamento/interação com os corpos em cena, enfatizando uma lógica narrativa dramática, calcada no diálogo.

Inserido no contexto de inovação tecnológica do MIT Film Section, o início da experiência de Diaries também dependeu do desenvolvimento de um modus operandi particular para a filmagem. Pincus afirma que assim que surgiram as possibilidades de filmar intimamente com uma boa imagem e um bom som também se criou a opção da feitura de Diaries (MacDonald, 2014: 96). Neste caso, o diretor ressalta o desenvolvimento de uma câmera Éclair relativamente menor que as outras (pesando apenas cinco quilos) e o gravador de fita magnética Nagra SN: uma peça de equipamento pequena o suficiente para que fosse carregada no bolso do cineasta ou em uma pequena bolsa a tiracolo. Mais particularmente, Diaries contou com um projeto desenvolvido por Ed Pincus e Stuart Cody, técnico do MIT Film Section, de ligação por sinal de rádio wireless entre a câmera e o gravador de fita magnética. Em termos práticos, no momento em que Pincus acionasse o funcionamento da câmera, o sistema emitiria um sinal de rádio para o gravador de fita magnética que também iniciaria a gravação. Desta forma, câmera e gravador poderiam estar desvinculados fisicamente e o acionamento de ambos dependeria apenas de uma pessoa (no caso, o próprio cineasta). Acoplado ao gravador estaria um microfone de lapela (lavalier), que possibilitaria que as pessoas filmadas por Pincus portassem o conjunto próximas de si. Em grande parte de Diaries este set-up foi usado, o que deixava livre uma das mãos do cineasta para a utilização de uma lente zoom. Esta, por sua vez, permitia o distanciamento entre Pincus e as pessoas filmadas com liberdade de enquadramentos dinâmicos. Em suma, tratava-se 
de alcançar o conjunto de possibilidades fílmicas do cinema direto a partir de uma equipe composta pelo cineasta, autossuficiente.

Há, como já frisado, um cenário pré-fílmico particular sobre o qual a experiência de Pincus se alicerça e que se pode detalhar. O cineasta e sua esposa estavam casados há onze anos. Ambos ideologicamente atentos aos movimentos sociais que circundavam o momento. Ed já era professor do MIT Film Section e Jane Kates Pincus possuía longo histórico como militante ativista, sendo uma das autoras de Our Bodies, Ourselves, primeiro guia coletivo estadunidense de saúde da mulher ${ }^{9}$. Ed e Jane decidem vivenciar uma experiência de casamento aberto: ambos poderiam viver casos extramaritais. $\mathrm{O}$ cineasta propõe um período de cinco anos de filmagem durante os quais acreditava que a família passaria por diversos tipos de transformações. Através desta estratégia, a matéria-prima de Diaries seria a maneira através da qual as pessoas apresentam mudanças de comportamento, opiniões, humores, estados de consciência, bem como transformações físicas, por um período de tempo prolongado. À fricção em potencial que seria causada tanto pelo casamento aberto quanto pelo crescimento dos filhos em meio a uma época de experimentação e reavaliação de valores seria adicionada a intenção em realizar um filme sobre a experiência.

Os motes mais significativos de Diaries são expostos pouco tempo após o início da narrativa. Em algumas das primeiras sequencias do filme, Jane, ao ser questionada pelo marido, revela seu desconforto com a empreitada fílmica que está sendo conduzida. Em suas respostas, a esposa do cineasta revela que a presença da câmera cria uma camada de autoconsciência que dificilmente poderia ser superada. Em uma de suas falas, Jane aponta: "Eu sinto que tenho de atuar, sendo que em minha vida toda tentei não fazer isto". Como uma reação ao cinema direto clássico, Diaries tematiza de antemão o flexionamento dos comportamentos dos personagens diante da câmera na circunstância da

9. No final dos anos 1960, Jane envolveu-se com um coletivo de mulheres da cidade de Cambridge, Bread and Roses, que reunia-se no MIT. Após uma conferência a respeito da saúde e do corpo feminino, Jane Pincus e outras ativistas desenvolveram o projeto de Women and their Bodies, publicado em 1970. Lançado inicialmente na forma de zine, a publicação partiu da troca das experiências pessoais das autoras, que organizaram o conhecimento ao longo de doze tópicos, como "Gravidez", "Controle de Natalidade", "Aborto", "Doenças Venéreas" e outros. O livro, escrito por mulheres e para mulheres, obteve largo reconhecimento ao tratar de tabus e tornou-se revolucionário por lidar abertamente com questões como a do aborto, ainda ilegal na época. Em 1973, o livro foi publicado pela editora mainstream Simon and Schuster já como "Our Bodies, Ourselves", nome que permanece até os dias atuais. "Our Bodies, Ourselves" é considerado o primeiro guia coletivo estadunidense de saúde da mulher e é reeditado, ampliado e reavaliado constantemente desde a década de 1970 , tendo sido reproduzido em mais de trinta línguas. Jane Pincus continuou a contribuir com as reedições do livro até o ano de 2005 . Em 1970-1971 Jane realizou o documentário Abortion, conjuntamente com outras três militantes, que contou com equipamentos, processamento e salas de montagem do MIT para sua produção. Apesar da pouca projeção pública, Jane Pincus afirma que o filme foi o primeiro sobre a temática do aborto a ser de fato finalizado nos Estados Unidos (MacDonald,2014: 99). 
tomada como condição sine qua non para o discurso fílmico, neste caso, autobiográfico. O fato do registro de Diaries alicerçar-se em um período de tempo prolongado - cinco anos - apresenta-se, também nesse sentido, como um importante ponto da experiência. Em texto escrito durante a captação do filme, em 1972, Pincus aponta que diferentemente de outros filmes do cinema direto, que procuram definir uma pessoa através do registro de um curto período de tempo, ele pode "olhar para as pessoas mais como estados de transformação. As pessoas podem ser tratadas mais como 'vir-a-ser"' (Pincus, 1972: 25. Tradução nossa.). Como consequência desta intenção de Pincus, Diaries revela narrativamente que, ao longo dos anos, a câmera e a "intenção fílmica" do cineasta acabam por tornar-se mais próximas da experiência cotidiana de sua família e das pessoas envolvidas na empreitada. Com o passar do tempo, a presença da câmera deixa de ser uma grande novidade para as crianças, da mesma forma que a performance de amigos e colegas de trabalho do diretor revela-se aparentemente mais incorporada à sensação de conforto e naturalidade. Dessas, a mudança de atitude de Jane em relação ao projeto é a mais palpável, sendo colocada em evidência na narrativa. Em entrevista a Scott MacDonald, Jane ressalta que o ódio que tinha em relação ao projeto no início das filmagens deu lugar a um desejo genuíno de ser filmada, ao reconhecer-se como uma mulher "realmente interessante" (MacDonald, 2014: 100).

Outra instância da transformação de pessoas e consciências, opiniões, desejos, humores e afetos consolida-se na abordagem temática do relacionamento amoroso entre o casal Pincus, que leva à consideração endossada pelo próprio diretor de que Diaries seria, em última instância, "uma história de amor" (MacDonald, 2014: 91). A experimentação do casamento aberto é tematizada nos primeiros minutos do filme, quando a narrativa apresenta Ann, uma das amantes do cineasta durante o período filmado. Ao longo das três horas de Diaries, são diversas as situações em que a interação entre os personagens - majoritariamente, entre Ed e Jane - revela a constante reavaliação da situação amorosa do casal, em meio à tematização de novas pessoas na vida de cada um deles. Decididamente mais instável do que harmoniosa, segundo o que o filme nos mostra, a experimentação do casal Pincus de uma alternativa à monogamia é abordada em diversas de suas discussões. Em cada uma delas, um novo cenário é disposto, no qual uma das partes se mostra menos satisfeita do que a outra em relação à situação "atual" da experiência. Não são incomuns demonstrações de ciúmes ou de indicações que sugiram o desejo de uma separação total do casal. Aproximando-se de seu final, entretanto, Diaries sugere o apaziguamento das tensões existentes entre o cineasta e sua esposa, bem como a decisão por estabelecer uma vida familiar nuclear - que 
culmina na mudança dos Pincus para o campo, em Vermont, onde a família permanecerá pelas próximas quatro décadas.

A busca por formas de relacionamento alternativas é uma das muitas características que faz Diaries apresentar-se como o retrato de uma época, consolidado a partir do visionamento da experiência particular da família Pincus. Ainda neste aspecto, Diaries tematiza uma postura pró-aborto (ainda proibido e ligado à causa feminista da década de 1970) ao mostrar o procedimento realizado por Jane em 1971. O naturismo é um ponto presente no filme, sendo recorrentes as sequencias em que vemos os corpos nus de praticamente todos os personagens envolvidos: Ed, Jane, seus filhos pequenos, seus amigos e amantes, em diversas situações nas quais parece haver pouco ou nenhum constrangimento em relação à câmera. A experimentação de drogas também é tematizada: ainda no início do filme, Pincus filma a si próprio durante uma "viagem" de mescalina durante uma visita à California, no chalé de Jim McBride (diretor do "falso" filme autobiográfico David Holzman's Diary [1968]). Em uma sequência próxima à metade do filme que aborda uma das discussões do casal, Jane reivindica uma reavaliação da divisão de trabalho dentro e fora de casa: a esposa questiona o fato de ter de cuidar da maior parte dos afazeres domésticos e do trato com as crianças enquanto Ed trabalha como professor, sugerindo pensarem em uma alternativa mais justa. Scott MacDonald frisa que o fato de Pincus tematizar estas questões consolida-se como uma confrontação à ideia de que o que se passava dentro da vida familiar, "desde quanto dinheiro eles ganham até a natureza de suas atividades sexuais" (MacDonald, 2013: 143), deveria manter-se em um âmbito privado. Através de seu filme, o realizador torna públicas estas e outras questões que constituíam um relacionamento matrimonial, bem como cristaliza episódios que dizem respeito a um cenário individual, mas que também se referia à realidade de outros jovens casais no início da década de 1970. MacDonald sustenta que Pincus foi um dos poucos cineastas que retratou as experiências desta geração, a partir de um ponto de vista de dentro da experiência, e as maneiras nas quais isto afetou a vida cotidiana dos casais e de suas famílias (MacDonald, 2013: 150).

São diversas as características metodológicas e estilísticas de Diaries, assim como sua estrutura narrativa, que endossam as opiniões de Pincus expressas em seus escritos e entrevistas da época. Evidentemente, o conjunto de inovações tecnológicas que antecederam o início de Diaries serviam não apenas a uma questão de minimização de gastos ou de praticidade, mas referiam-se sobretudo à visão artística de Pincus em relação a um tipo de narratividade autobiográfica possibilitada por uma nova conjuntura. Sem negar a ligação com a tradição do cinema direto estadunidense, em Diaries Pincus almejava 
trabalhar a "sensação de estar lá", porém voltada para o universo das interações domésticas e cotidianas, fazendo-se de si próprio um personagem ativo do filme. A matéria prima imagética-sonora de Diaries é composta através de tomadas realizadas em situações não deslocadas, ou pouco deslocadas, do cotidiano "normal" do cineasta e das pessoas filmadas. A experiência de Pincus, segundo sugere Jim Lane, enfatiza a importância de tornar o cotidiano visível como uma maneira de explorar a "natureza da subjetividade e das interações humanas, que a câmera tem a capacidade única de retratar" (Lane, 2002: 53). Sendo assim, ao empunhar a câmera (e o gravador de som) em situações integradas a seu cotidiano, Pincus via neste tipo de registro uma maneira particular de escrita autobiográfica, que sobrepunha substancialmente a tomada fílmica ao "ato de viver". A consubstancialidade do registro de imagem e som a uma circunstância de situação dramática que reconhecemos como pertencente à vida pessoal do cineasta confere uma noção à tomada de escrita autobiográfica no "tempo presente" e que parte de uma motivação existencial distinta da dos textos escritos.

À maneira através da qual a narratividade de Diaries é conduzida subjaz o comprometimento de Pincus com a noção de uma narrativa autobiográfica calcada na potencialização da referencialidade de seu discurso. $\mathrm{O}$ diretor enfatiza procedimentos narrativos que construam uma experiência "palpável" dos eventos profílmicos: o mundo material, da maneira que é apresentado à câmera na circunstância da tomada fílmica. Nesta circunstância, não apenas as palavras pronunciadas, mas os gestos feitos, os silêncios, o mundo concreto dos objetos, tudo isto adquire relevância e significado em uma narrativa autobiográfica investida em explorar momentos cotidianos da relação entre o cineasta e as pessoas ao seu redor. Um artigo da revista Film Comment publicado em 1981, logo após o lançamento de Diaries, ressalta aspectos análogos a estes como uma das particularidades da empreitada fílmica de Pincus. O autor Stephen Schiff sublinha a relação entre os estados de consciência do realizador, particularizados pelo momento da tomada, a e sua expressão fílmica-corpórea que vemos na tela:

O falecido fenomenólogo Maurice Merleau-Ponty acreditava que um homem expressa o "todo" de seu ser não apenas no que ele diz e faz, mas nas minúcias de seus movimentos, o jeito que ele gesticula, a maneira que ele anda pelo espaço de uma sala, ou mesmo que ele lança um olhar sobre um objeto distante. Os movimentos da câmera de Pincus transmitem quem ele é da mesma maneira que qualquer ação intencional, e, assistindo a eles, nós o descobrimos como um auteur de uma maneira que nunca poderíamos descobrir Hitchcock, Welles ou Ophuls. Este é um processo misterioso, mas não precisa parecer tão obscuro. A perícia de Pincus na composição dos quadros, por exemplo, varia ao longo do filme, dependendo não apenas de seu objeto (...), mas tam- 
bém de seu estado de consciência. O quão mais calmo e mais confiante está Pincus, mais bonitas são suas tomadas. (...). Com a maturação de si próprio e de Jane, com a brandura de seus problemas, o estilo cinemático torna-se mais preciso e mais pitoresco. (Schiff, 1981. Tradução nossa.).

Algo semelhante ao apontamento de Schiff é encontrado no artigo de Susanna Egan, que podemos citar novamente. Egan ressalta a maneira através da qual estes filmes autobiográficos remetem-se à "experiência original" do cineasta, ao tornar visíveis os elementos materiais e interações interpessoais que, no limite, dizem respeito diretamente à sua vida cotidiana. Ressaltando a ideia de consubstancialidade entre a expressão fílmica e a realidade fenomenal, Egan sugere a expressão "irromper" (ou "transbordar", burst out) ao apontar a relação da experiência individual do cineasta com aquilo que é transposto no registro fílmico: "a mobília, os aposentos, o cenário e as pessoas irrompem do quadro como um lembrete constante daquela experiência original a que a experiência filmada se refere". (Egan, 1994: 607).

É possível dizer que Pincus constrói a narrativa de Diaries como o teste de uma hipótese, sendo que o diretor se abstém de investir em elementos estilísticos ou metodológicos que fujam desta lógica referencial. Na medida em que a interação entre os corpos em cena (e também do cineasta) com o mundo das superfícies é a principal matéria-prima de Diaries, o realizador abre mão quase totalmente de utilizar recursos estilísticos que não frisam narrativamente sua particularidade espaço-temporal. É o caso da utilização econômica de ferramentas como a narração em voz over, que no filme porta uma função bastante restrita. Em sua utilização mais comum, a narração em over não traz consigo clareza ontológica em relação ao momento em que foi escrita ou gravada. Além disso narrações em over são, dominantemente, fruto de uma atividade prolongada de esforço racional, que resulta em discursos coerentes, dotados de densidade analítica e juízos de valor. Como contraponto, é possível sugerir que indivíduos dificilmente apresentam rigor analítico conceitual irretocável nas interações que travam com outras pessoas, na grande maioria dos cenários cotidianos. Com Diaries, Pincus buscava explorar narrativamente este ponto, ao retratar a si próprio e as pessoas ao seu redor não na performance de suas expertises intelectuais, mas na performance daquilo que é ordinário: menos em suas condições de mitos e mais como seres passíveis de incongruências, hesitações, contradições ou sensíveis a alterações de temperamento. Em entrevista a Scott MacDonald, Pincus toca nesta questão ao sustentar que "a maioria das coisas que as pessoas dizem são estúpidas. Durante a edição de Diaries, pensava 'Meu Deus, eu realmente disse isso? Ela realmente disse isso?'. Mas, estúpido ou não, aquilo que dizemos é parte essencial daquilo que somos" (MacDonald, 2014: 96). Semelhantemente, em texto de 1977, Pincus sublinha 
o aporte metodológico que rege a empreitada de Diaries, asserindo que "Tudo pode ser dito em entrevistas ou na narração em over, mas nem tudo pode ser mostrado. Talvez a principal preocupação do cinema agora seja aquilo que não pode ser dito, mas deve ser mostrado" (Pincus, 1977: 175).

Finalmente, outro comprometimento conceitual de Ed Pincus em relação a Diaries que aponta para a tradição do cinema direto, é a disposição de uma macroestrutura narrativa cronológica. Segundo aponta Jim Lane, originalmente Pincus estaria convencido de que o projeto completo de Diaries seria a exibição das 27 horas de seu material bruto em ordem cronológica (Lane, 1997: 10), ideia esta que foi deixada de lado alguns anos após o término da filmagem. Entretanto, a narrativa, embora longa, é conduzida a partir de uma estrutura de causa-e-efeito, responsável pela manutenção do interesse dramático em relação a alguns pontos temáticos principais do filme - em especial, a discussão acerca da vida conjugal de Ed e Jane, que entrecorta toda a narrativa. De maneira geral, a espectatorialidade de Diaries consiste em uma espécie de fluxo no qual imerge-se aos poucos até que se torne pleno o entendimento de sua proposta narrativa. No início do filme, Pincus não enfatiza procedimentos narrativos que nos apontem o que devemos buscar na experiência audiovisual à qual estamos expostos. Da mesma forma, existe pouco didatismo quando novos personagens são apresentados à narrativa - pouco sabemos, em um primeiro momento, da relação entre o personagem e o cineasta que justifique sua inclusão no filme. É neste aspecto que a reexposição dos personagens a partir de uma narrativa cronológica faz com que ao longo do filme emerjam traços de seus comportamentos físicos, personalidades, mudanças de temperamento e do tipo de laço que mantém com o cineasta, sempre a partir de interações dramáticas com outros personagens ou com o próprio Pincus. Também neste sentido o autor Stephen Schiff disserta a respeito de como o sentido da narrativa de Diaries é construída em seu visionamento:

Ao estender tão pouco material sobre uma extensão (de tempo) tão ampla, Pincus fez com que a pele de seu filme parecesse esticada e resiliente. Saltando de um incidente parcialmente esboçado para outro, o espectador começa a preencher as lacunas e a sensação que (este procedimento) transmite é bastante como um suspense. É como se Diaries desencadeasse algum impulso narrativo inconsciente - um poder de conexão enevoante, aglutinador, não diferente da persistência da visão que transforma as fotos em filme quando elas são piscadas vinte e quatro vezes por segundo. Aliviadamente, Diaries não insiste em sua narrativa. A estória simplesmente forma-se, coalesce, tão misteriosamente como a geada em uma janela. O que é surpreendente é que há uma história, que quando olhada em pedaços como este, (mostra que) a vida produz narrativa, repleta de seus próprios motes, viradas e trechos de suspense. Você consegue ver isso acontecer. (Schiff, 1981. Os grifos são do autor. Tradução nossa.). 


\section{Considerações Finais}

A contribuição de Diaries (1971-1976) para história do cinema documentário reside no fato de que o filme inaugura um dos conjuntos estilísticosmetodológicos que se tornou canônico em nossa noção atual de documentário autobiográfico. Por meio do pensamento de cineastas como Ed Pincus e do trabalho desenvolvido no MIT Film Section, apresentou-se o desdobramento do cinema direto em direção à proposta autobiográfica, que deste momento em diante tornar-se-á uma demanda crescente na cinematografia dos Estados Unidos e de outros países. É importante notar como a visão cinematográfica de Pincus distinguia-se de outros conjuntos de valores fílmicos que eram contemporâneos ao seu trabalho. Quanto a estes, pode-se mencionar a reflexividade presente no cinema-vérité de Jean Rouch (cuja distinção é exemplificada no debate entre ambos exposta neste artigo) ou a noção de autobiografia que permeava o cinema avant-garde estadunidense na forma de Jonas Mekas, Stan Brakhage e outros, aos quais Pincus denominava "um reino totalmente diferente" do cinema (Pincus, 1977: 171).

O cenário acadêmico de Cambridge apresenta-se como um repositório de cineastas que se utilizaram de metodologias derivadas do cinema direto para a construção narrativa de conhecimento autobiográfico. Para além de Ed Pincus - e por meio de sua influência - é possível mencionar cineastas relacionados a este momento, como Miriam Weinstein, Robb Moss e Ross McElwee. McElwee, por sua vez, é o principal responsável pela popularização do documentário autobiográfico como gênero e tornou-se influência maior que Pincus para diversos cineastas que buscaram seguir por esse caminho. Outros documentários autobiográficos contundentes realizados mais tarde, como Silverlake Life: The view from here (Tom Joslin e Peter Friedman, 1993), partem do conjunto valorativo do cinema direto para servir a uma ótica de autobiografia e, de certa forma, apontam historicamente para o ambiente de inovação proposto décadas antes no MIT Film Section.

Finalmente, é importante lembrar que para além dessas, existem diversas outras propostas metodológicas possíveis para o cumprimento de determinadas visões artísticas autobiográficas. Pode-se pensar no trabalho autobiográfico de Jonas Mekas, como citado, ou no paradigmático Tongues Untied, dirigido por Marlon Riggs em 1989, como filmes desassociados a qualquer noção de cinema direto. Diferentemente, estes são filmes que tendem a contar com procedimentos como o resgate da memória via voz over, a fragmentação cronológica ou emprego de dramatizações e reencenações, e apresentam-se como exemplos em relação às várias maneiras através da qual o conhecimento autobiográfico pode ser construído em narrativas documentárias. 


\section{Referências bibliográficas}

Aufderheide, P. (1997). Public intimacy: the development of first-person documentar. Afterimage, 25.1. Rochester.

Egan, S. (1994). Encounters in camera: autobiography as interaction. Modern Fiction Studies, 40 (3): 593-618. Baltimore.

Lane, J. (2002). The autobiographical documentary in America. Madison: The University of Winsconsin Press.

Lane, J. (1997). The career and influence of Ed Pincus: shifts in documentary epistemology. Journal of Film and Video, 49 (4): 3-17. Chicago.

Levin, G. (1971). Documentary explorations. 15 interviews with film-makers. Garden City: Doubleday.

MacDonald, S. (2014). Avant-doc: intersections of documentary and avantgarde cinema. Nova Iorque: Oxford University Press.

MacDonald, S. (2013). American ethnographical film and personal documentary. The Cambridge turn. Londres e Los Angeles: University of California Press.

MacDonald, S. (1988). Southern exposure: interview with Ross McElwee. Disponível em: www.pbs.org/wgbh/pages/frontline/shows/news/ross/fil mquart.html

McElwee, R. (2012). An appreciation: Ed Pincus' diaries by Ross McElwee. Disponível em http://hcl.harvard.edu/hfa/films/2012aprjun/pincus_note.h tml

McElwee, R. (1977). Three experiments in cinema-vérité. Cambridge: Dissertação de Mestrado, Massachusetts Institute of Technology.

Moss, R. (1979). Riverdog journal. Cambridge: Dissertação de Mestrado, Massachusetts Institute of Technology.

Nichols, B. (2015). Speaking truths with film: evidence, ethics, politics in documentary. Los Angeles: University of California Press.

Parry, D. (1979). Personal cinema in family crisis situations. Cambridge: Dissertação de Mestrado, Massachusetts Institute of Technology.

Peña, R. (1978). Some current problems in the vérité approach to film/video documentaries. Cambridge: Dissertação de Mestrado, Massachusetts Institute of Technology.

Pincus, E. (1977). New possibilities in film and the university. Quarterly Review of Film Studies, 2 (2): 159-178. Londres. 
Pincus, E. (1972). One person sync-sound: a new approach to cinema vérité. Filmmakers Newsletter, 6 (01): 24-30. Michigan.

Rance, M. (1977). Home movies. Cambridge: Dissertação de Mestrado, Massachusetts Institute of Technology.

Roston, T. (2012). In the midst of a retrospective, a lesson from filmmaker Ed Pincus. Disponível em www.pbs.org/pov/blog/docsoup/2012/11/in-themidst-of-a-retrospective-a-lesson-from-filmmaker-ed-pincus/.

Rothman, W. (1997). Documentary film classics. Cambridge: Cambridge University Press.

Rothman, W. (1996). Eternal vérités. In C. Warren (ed.), Beyond document: essays in nonfiction film (pp. 79-99). Wesleyan: UP/UP of New England.

Schiff, S. (1981). Camera man. Disponível em www.filmcomment.com/articl e/ed-pincus-diaries.

Warren, C. (2016). Cinema direct and indirect, American Documentary 19601975. In American film history: selected readings, 1960 to the present (pp. 56-71), West Sussex: John Wiley and Sons.

Warren, C. (2013). Pincus, Edward. In I. Aitken (ed.), The concise Routledge encyclopedia of documentary film (pp. 718-719). Nova Iorque: Routledge.

Warren, C. (1996). Introduction. In C. Warren (ed.), Beyond document: essays in nonfiction film (pp. 1-22). Wesleyan: UP/UP of New England.

Winston, B. (1993). The documentary film as scientific inscription. In M. Renov (ed.), Theorizing documentary (pp.37-57). Nova Iorque: Routledge.

\section{Filmografia}

Absence (1981), de Robb Moss.

Black Natchez (1967), de Ed Pincus e David Neuman.

Breaking and Entering (1980), de Ann Schaetzel.

Bright Leaves (2004), de Ross McElwee.

Chronique d'un été (1961), de Jean Rouch e Edgar Morin.

Crisis: Behind a Presidential Commitment (1963), de Robert Drew.

David Holzman's Diary (1967), de Jim McBride.

Death and the Singing Telegram (1983), de Mark Rance.

Demon Lover Diary (1980), de Joel DeMott. 
Diaries (1971-1976) (1980), de Ed Pincus.

Jane (1962), de Albert e David Maysles.

Mom (1978), de Mark Rance.

Nuit et Brouillard (1955), de Alain Resnai.

One Step Away (1968), de Ed Pincus e David Neuman.

Premature (1979), de David Parry.

Primary (1960), de Robert Drew.

Riverdogs (1982), de Robb Moss.

Sherman's March (1986), de Ross McElwee.

Showman (1962), de Albert e David Maysles.

The Plaint of Steve Kreines as recorded by his younger brother, Jeff (1974), de Jeff Kreines.

The Same River Twice (2002), de Robb Moss.

The Tourist (1991), de Robb Moss.

Time Indefinite (1993), de Ross McElwee.

Titicut Follies (1967), de Frederick Wiseman. 